\title{
Fluorescence imaging agents in cancerology
}

\author{
Aurélie Paganin-Gioanni ${ }^{1,2}$, Elisabeth Bellard ${ }^{1,2}$, Laurent Paquereau ${ }^{1,2}$, Vincent Ecochard ${ }^{1,2}$, \\ Muriel Golzio ${ }^{1,2}$ and Justin Teissié1,2 \\ 1 CNRS; IPBS (Institut de Pharmacologie et de Biologie Structurale); Toulouse, France \\ 2 Université de Toulouse; UPS; IPBS; Toulouse, France
}

Received 13 January 2010

Accepted 4 May 2010

Correspondence to: Muriel Golzio and Justin Teissié, CNRS; Institut de Pharmacologie et de Biologie Structurale, 205 route de Narbonne, F-31077 Toulouse, France. E-mail: muriel.golzio@ipbs.fr; justin.teissie@ipbs.fr

Disclosure: No potential conflicts of interest were disclosed.

Background. One of the major challenges in cancer therapy is to improve early detection and prevention using novel targeted cancer diagnostics. Detection requests specific recognition. Tumor markers have to be ideally present on the surface of cancer cells. Their targeting with ligands coupled to imaging agents make them visible/detectable. Conclusions. Fluorescence imaging is a newly emerging technology which is becoming a complementary medical method for cancer diagnosis. It allows detection with a high spatio-temporal resolution of tumor markers in small animals and in clinical studies. In this review, we focus on the recent outcome of basic studies in the design of new approaches (probes and devices) used to detect tumor cells by fluorescence imaging.

Keywords: Photonic imaging; fluorescence; cancerology; apramers; smart probes

\section{State of the art}

Specific visualization of carcinogenesis or established tumor cells offers opportunities to guide surgery and monitor the response to therapy. In the clinic, radio-imaging uses contrast agents Indium-111 and Technetium-99 coupled to antibodies to target prostate ${ }^{1,2}$, colorectal ${ }^{3}$, ovarian ${ }^{4}$ or small-cell lung cancers. ${ }^{5}$ These radioelement-based technologies are powerful tools for the detection and therapy of cancers but they cannot be used during surgery. Fluorescence imaging is more user-friendly and provides on-line information. Therefore, fluorescence imaging agents which allow fast detection with a high spatio-temporal resolution can increase detection of the edge of the primary tumor, the presence of metastasis and therefore help tissue resection by the surgeon.

\section{Fluorescence imaging}

\section{Why the NIR (near infra red) light?}

In tissue fluorescence imaging, it is necessary to take into account five important parameters: reflec- tion, absorption, refraction, background autofluorescence and distribution of photons emitted by the fluorochrome targeted to tissues. Skin is an obstacle because the emitted light is reflected by this barrier and this reflection brings a loss in the penetration of the excitation light.

In tissue, different chromophores in biomolecules strongly absorb the incident (or emitted) light. This is a major limit for the near UV and visible part of the spectrum. Light absorption by hemoglobin is a problem in the visible range (from 400 to $670 \mathrm{~nm}$ ). Indeed, the absorption coefficient $\left(\mathrm{cm}^{-1}\right)$ decreases when the wavelength increases. Absorption due to the chromophores in biomolecules is very strong below $460 \mathrm{~nm}$ and remains important up to $580 \mathrm{~nm}$. Thus, only a weak penetration in the tissue can be obtained. The same problem is of course present if emission is in the same wavelength range as absorption. A deeper penetration is obtained when working in the near infrared (NIR) part of the spectrum between 600 and 1000 nm (Figure 1). ${ }^{6}$ The upper limit in the wavelength (around $1200 \mathrm{~nm}$ ) is due to water which is a strong light filter in IR spectroscopy.

Light scattering due to turbid media is also reduced in this high wavelength window as predict- 
ed by the Rayleigh law. Nevertheless, scattering in tissues remains high, due to refractive index mismatches between the different cellular components and fluids. This is a limit in the spatial definition.

Finally, light absorption by endogenous tissue fluorochromes can result in light emission, the so called autofluorescence of the tissue. This phenomenon is due to the oxidized forms of riboflavin, the co-enzymes flavin and NADH reduced inside cells. ${ }^{78}$ Other molecules like lipofuscin and ceroides or other components of the skin, such as collagen and melanin, also contribute to this effect. Autofluorescence is also a consequence of food that contains chlorophyll. ${ }^{9,10}$ Tissue autofluorescence is mainly present in the UV and visible range of the spectrum.

Compared to fluorescence imaging in the visible light range, fluorescence imaging in the NIR bandwidth offers less photon absorption by blood hemoglobin, lipid and water, and a limited light scattering, enabling photon transmission deeper into the body. Thus, substantially reduced tissue autofluorescence, enabling higher sensitivity detection of target NIR molecular imaging agents due to a low background, can be achieved.

For a greater discussion of the physics underlying efficient NIR photon delivery through tissues, fluorescence chemistry synthesis approaches and fluorescence hardware systems, the interested reader can consult several reviews. ${ }^{11,12}$

As a conclusion, an accurate quantitative and spatially resolved detection in vivo by an optical method faces intrinsic limitations due to the optical properties of intact biological tissues. Taking into account these optical properties of living tissues, optimized conditions by choosing the relevant biological reporter fluorophores could be obtained.

\section{Which fluorophore?}

Two kinds of commercial organic fluorochromes emitting in the NIR wavelength domain are available: cyanine ${ }^{13}$ and Alexa Fluor. ${ }^{14}$ They can be grafted on any kind of molecules of interest such as nucleic acids, proteins or antibodies. They have several advantages such as weak toxicity, a small molecular weight, a functional group allowing their grafting and weak photo-degradation. Their limit is a weak fluorescent quantum yield. ${ }^{13}$ Therefore, multigrafting of these molecules on "rafts" 15 or on dendrimers ${ }^{16}$ is performed to overcome this problem by increasing the local number of emitters on the target. Company brand fluorophores are now

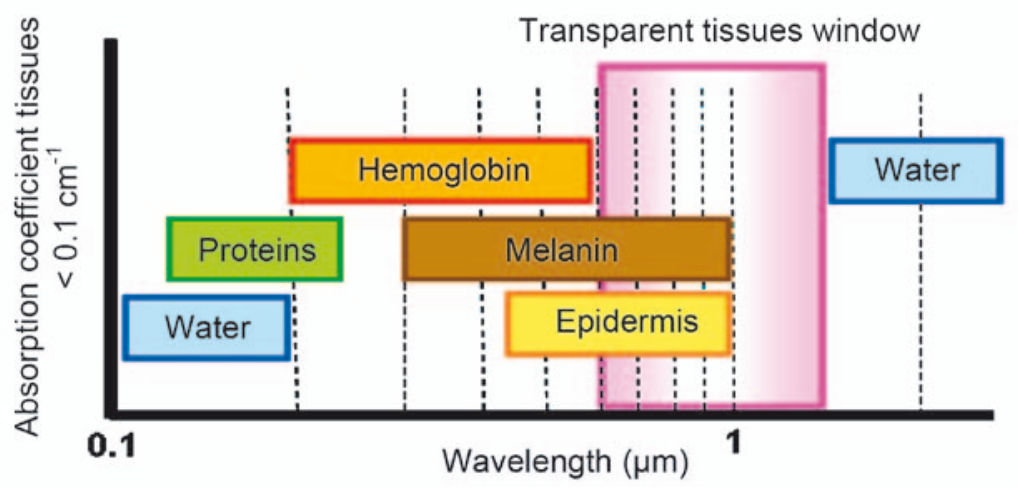

FIGURE 1. Absorption spectra of different molecules present in biological tissues. The tissue optical window (600-1200 nm) is ideally sought in fluorescence imaging of small animals. Hemoglobin and water absorb light below and above the optical window.

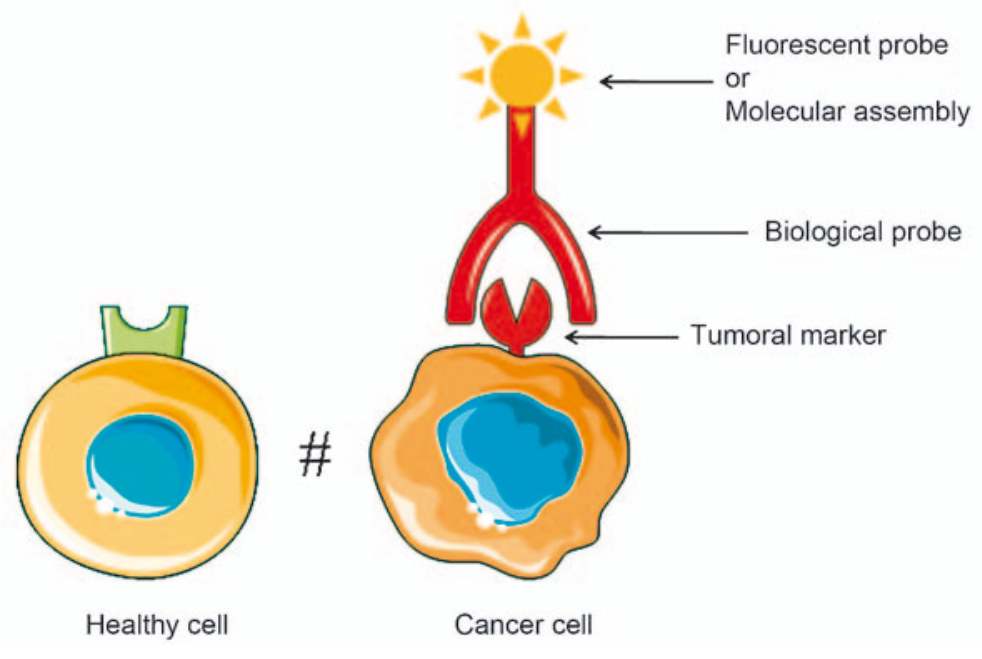

FIGURE 2. Principle of targeting tumor cells by fluorescence imaging.

on the market (DyLight Fluor family by Dyomics in collaboration with Thermo Fisher Scientific, KODAK X-SIGHT Large Stokes Shift Dyes and nanospheres, XenoLight CF by Caliper).

Commercially available quantum dots are promising competitors of organic probes for fluorescent imaging ( $\left(\operatorname{Qdot}^{\circledR}\right.$ nanocrystals by Molecular probes, Quantum Dot Corporation Qtracker). Indeed, they have a strong fluorescent quantum yield $^{13}$, a weak sensibility to photobleaching and a strong stability. However, they have significant toxicity in vivo due to their chemical core (nanotoxicology). ${ }^{17}$ In vivo, they are used with success in biphoton microscopy and some reports are cited in small animal imaging studies. ${ }^{18}$ 


\section{Probe design}

Targeting tumor cells by fluorescence imaging can be achieved by coupling a fluororescent agent with biological probes (antibodies, aptamers, peptides or enzymatic ligands or metabolites) that recognize specific tumor markers only expressed or over-expressed by tumor cells. The labeling of the biological probes can be done by fluorescent markers or complex molecular assemblies (Figure 2).

\section{Tumor markers}

Tumor cells differ from healthy cells by tumor markers which are expressed and located on their plasma membrane. These tumor markers are proteins or glycoconjugates over-expressed on the membrane surface of tumor cells such as protein receptors that interact with a panel of probes (or ligands) described in the following paragraph.

Several membrane antigens are recognized by monoclonal antibodies and used for imaging of tumors: prostate specific membrane antigen (PSMA) 16,19,20, the carcino embryo antigen (CEA) 21 , the VEGF receptor (Vascular Endothelial Growth Factor) or the Human Epidermal Growth Factor Receptor-2 (HER-2). ${ }^{22,23}$ These antigens are membrane proteins over-expressed by tumor cells and involved in life processes such as exogenous or endogenous transduction of signals or the cell cycle. In addition, they can be used in imaging to detect various tumors.

PSMA is a membrane and cytoplasmic glutamate carboxypeptidase which is involved in the cell cycle and in carcinogenesis associated with prostate cancer. CEA is involved in cell adhesion and is found in various cancers such as colorectal, gastric, pancreatic, lung and breast cancers. The VEGF receptor is over-expressed in most tumor and endothelial cells involved in angiogenesis. HER-2 is a tyrosine kinase membrane receptor involved in signal transduction pathways inducing growth and cellular differentiation. It is overexpressed in breast and ovarian cancers and other carcinomas.

There are other proteins over-expressed on the surface of several types of tumor cells such as metalloproteinase-2 (MMP-2) ${ }^{24}$, integrins $\alpha \mathrm{V} \beta 3{ }^{25,26}$ and lectins. ${ }^{27}$ These molecules are less specific for tumor cells than the antigens described above because they are also expressed by healthy cells but in much smaller quantities. Their natural ligands are used as probes.

\section{Biological probes}

Antibodies. Antigenic tumor markers used in molecular imaging are generally derived from anatomopathological tissues studies. A large library of antibodies specific for tumor cells has been gathered. They have been adapted for human administration (humanized and recombinant antibodies). Monoclonal antibodies are widely used in fluorescence imaging due to their strong affinity for their target. On the other hand, one should keep in mind their disadvantage of triggering immune reactions. It is difficult to find a good compromise between modifications (humanization, chimerization) of antibodies to make them more biocompatible and their loss of affinity for their target. Several monoclonal antibodies are available for in vivo fluorescence imaging applications: the anti-PSMA antibody that targets prostate tumor cells ${ }^{20,28}$, the anti-CEA antibody that targets tumor cells of prostate, pancreas and colorectal cancer ${ }^{29,21}$, the antiVEGF receptor antibody that targets tumor cells and those associated with the angiogenic process ${ }^{30}$ or the anti-HER-2 targeting tumor cells in breast, ovary, and other carcinomas (Table 1). ${ }^{23,31}$

Peptides and proteins. Peptides or proteins can also be used to target tumor cells but they are still at an experimental stage. This approach consists of using the binding properties of the peptide (or protein) with glycoconjugates or membrane proteins over-expressed in tumor cells (Table 1). For example, Chlorotoxin is used to detect various tumor cells (glioma, medulloblastoma, prostate cancer, bowel cancer and sarcomas). ${ }^{24}$ This peptide, derived from scorpion venom, is composed of 36 amino acids with 4 disulfide bonds and interacts with MMP-2. Due to its anti-cancer properties, it can be used to target tumor cells. In vivo detection of cells over-expressing MMP-2 was obtained by non-invasive fluorescence imaging. ${ }^{24}$ Cyanine 5.5 was coupled to primary amines of Chlorotoxin (3 amino functions). Another example is the RGD peptide, which is a cyclo-peptide that mimics angiotensin. It is used to detect tumor cells because it specifically interacts with $\alpha_{\mathrm{v}} \beta_{3}$ integrins overexpressed on the surface of many different tumor cells. $^{25,26}$

Metabolites. Another approach is to use metabolic properties of tumor cells that differ from normal cells. Indeed, they absorb more nutrients because they over-express proteins involved in cell growth. Thus, administration of metabolites is used to target receptors over-expressed in tumor cells (Table 1). For example, albumin that interacts with 
TABLE 1. Examples of tumors markers and probes used in fluorescence imaging

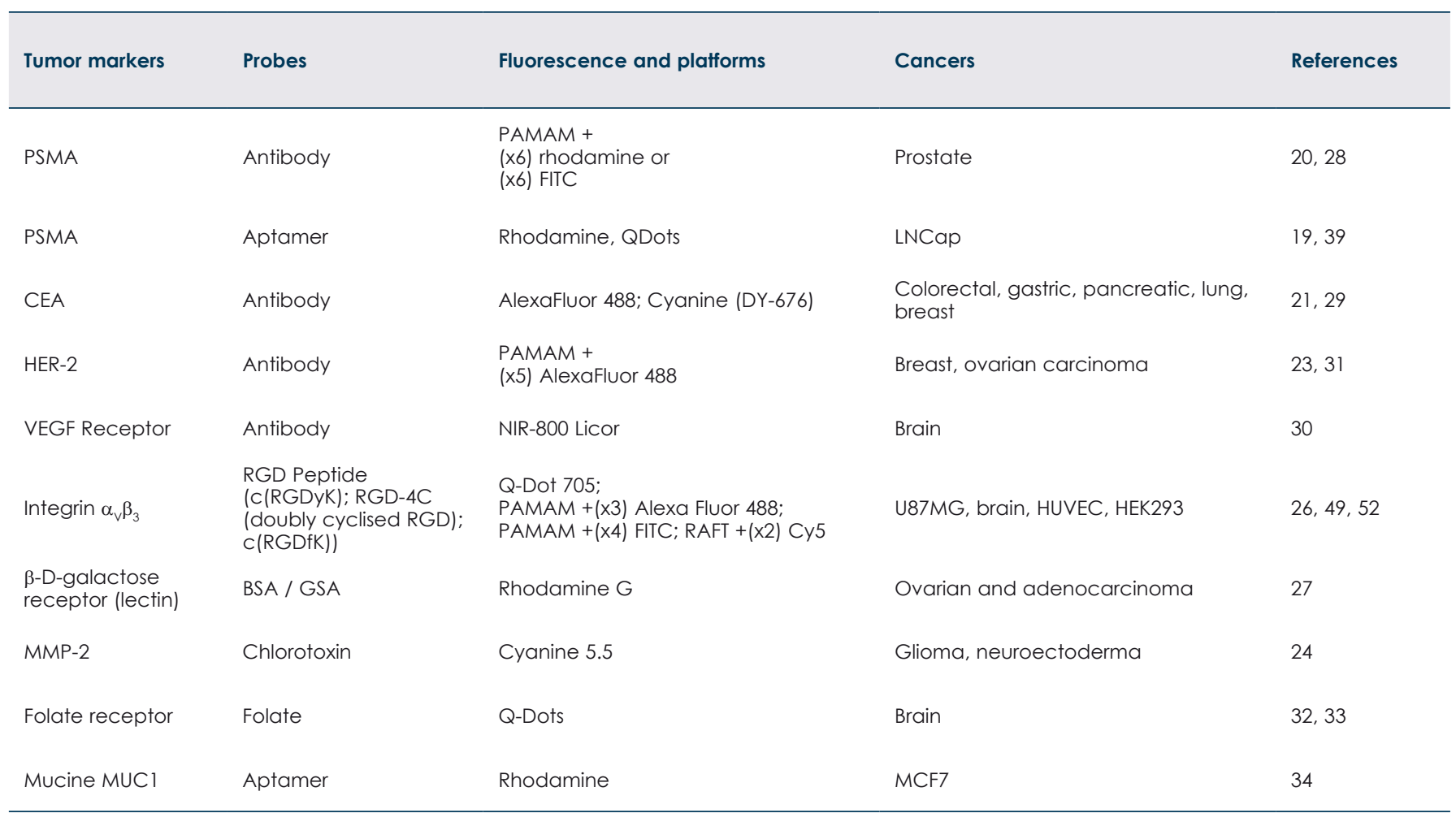

the $\beta$-D-galactose receptor ${ }^{27}$ or folic acid (vitamin B9) that interacts with the folate receptor (or folatebinding protein (FBP) ${ }^{32,33}$, are both effective for locating various tumor cells (ovary, kidney, uterus, brain, colon, lung adenocarcinoma). This approach is less specific for tumor cells than approaches targeting tumor antigenic markers but it is widely used in imaging modalities such as MRI and PET for the specific detection of tumor cells and also for drug-targeted delivery to tumors.

Aptamers. Aptamers can be used for targeting live cells. Aptamers are highly structured oligonucleotides selected by Systematic Evolution of Ligands by Exponential Enrichment (SELEX) to bind tightly (nanomalor range) and specifically to a target molecule. Recently, specific aptamers have been selected against tumor markers like PSMA or MUC1 (Table 1). ${ }^{19,34}$

Nucleotidic aptamers present all characteristics, which make them suitable as imaging probes: they are smaller (10-15 kDa) than antibodies (150 kDa), hence they exhibit higher tissue penetration and faster blood clearance. In addition, compared with antibodies, aptamers present a low immunogenicity, are not toxic and they can be chemically modified. ${ }^{35}$
The first aptamer used in imaging was designed against human neutrophil elastase. ${ }^{36}$ This work demonstrated for the first time the potential feasibility of using an aptamer labeled with technetium$99 \mathrm{~m}\left({ }^{99 \mathrm{~m} T c}\right)$ as reagents for diagnostic imaging. The aptamer had a signal-to-noise ratio higher and more rapid than the antibody.

More recently, an aptamer labeled with ${ }^{99 \mathrm{~m} T c}$ directed against human tenascin- $C$ was also used for in vivo imaging. ${ }^{37}$ These authors showed a rapid uptake of aptamers by tumor and a rapid clearance from blood and other non-target tissues, which enabled clear tumor imaging.

Another report used ${ }^{99 \mathrm{~m}} \mathrm{Tc}$-labeled-aptamer directed against MUC1 and was tested in MCF-7 tumor-bearing mice. ${ }^{38}$ Their first results showed the necessity to optimize the radiolabeled aptamer in terms of pharmacokinetics prior to use in imaging.

Actually, fluorescently-labeled aptamers that bound the tumor cell surface were either used for in vitro imaging on culture cells that expressed, for example, PSMA ${ }^{39}$ and MUC1 ${ }^{34}$, or by injections of a fluorescent aptamer against tenascin-C into tumorbearing mice followed by fluorescence microscopy on tissues sections. ${ }^{37}$ However, they are still not often used in fluorescence imaging of small animals. 
Smart probes. "Smart probes" or "smart sensors" are probes activated by an intracellular proteolytic reaction of targeted tumor cells that become fluorescent. These probes give an excellent signal-tonoise ratio because they are activated only when internalized in target cells. Basically, they are activated by proteases or intracellular reductases (metalloproteinases MMP-2, cathepsins B and D, cysteine proteases, thioreductases) over-expressed in tumor cells which cut Lys-Lys or disulfide bonds of the complex and release the fluorophore. ${ }^{35,40}$

ProSense probes developed by Weissleder (VisEn Medical, Inc., Woburn, MA) are polylysines labeled by non-fluorescent cyanines. When the probe is internalized into cells by endocytosis, the peptide link (between lysines) separating the cyanines is broken by the action of intracellular proteases such as cathepsins (B or D) or metalloproteinases (MMP-2) and fluorophores are released into the cells which become fluorescent. ${ }^{24,41}$

Razkin et al. have shown that the molecule RAFTRGD-Cy5-SS-Q penetrates effectively and specifically in tumor cells and is activated once inside. The complex consists of 4 RGD peptides specifically targeting the $\alpha \mathrm{V} \beta 3$ receptors over-expressed on the surface of cancer cells, and of a quencher (Q) connected to a cyanine 5 via a disulfide bond. This bond is reduced by thioredoxin in the cytoplasm and endosomes after internalization into cells. Once internalized, the quencher is spatially separated from the cyanine and the complex becomes fluorescent. The phenomenon of quenching can be achieved by combining two identical fluorophores but the rate of cleavage of the disulfide bond is weaker and the contrast obtained in vivo is much smaller. ${ }^{40}$

Engelman et al. demonstrated that the $\mathrm{pH}$ low insertion peptide ( $\mathrm{pHLIP}$ ) is able to insert into the lipid bilayer of the plasma membrane by forming an $\alpha$ helix when the acidity increases in the extracellular matrix. ${ }^{42}$ Indeed, the extracellular matrix surrounding tumors and areas of inflammation or infection are relatively acidic environments compared to healthy tissues. The insertion of the peptide in the cell membrane occurs at a $\mathrm{pH}$ below 6.5. The $C$ terminal end of the complex is translocated into the cytoplasm. Two applications are then possible - the targeted delivery of drugs in tumor cells and the fluorescence imaging of these cells. Engelman et al. first grafted a disulfide bond to the $\mathrm{C}$ terminal end of the peptide, linking it to a fluorescent molecule or a drug that can be released into the cells by cleavage of the disulfide bond by thioredoxin. They also showed that this peptide is effective in vivo for detection of tumor cells by noninvasive fluorescence imaging. It is shown that this peptide localizes specifically in tumor cells within 20 hours. $^{43}$

Molecular assemblies. Functionalization of fluorescent agents by coupling with enzymatic ligands ${ }^{44}$, antibodies ${ }^{45}$ or peptides ${ }^{46}$, enable their targeting to tumor cells. Classically, tumor probes are bound to an organic fluorophore ${ }^{45,21}$ or quantum $\operatorname{dot}^{28,31}$ to visualize tumor cells by fluorescence imaging. The commercial fluorophores have reactive groups such as amine, carboxylic acid or thiol of the amino acid of the protein probe. However, the number of reactive groups per probe is low. According to protein size and the number of reactive groups, 4 to 10 fluorophores can be grafted per protein. In order to increase the fluorescence signal of tumor probes and/or increase their specificity for target cells, molecules called "platforms" were used as a covalent support to several fluorophores and/or several probes (Table 1).

The quantum dots can be used as "platforms" because they allow several connections with biological probes. Cai et al. have shown this with the RGD peptide by grafting multiple RGD peptides onto a quantum dot. ${ }^{26}$ This greatly increases the specificity of quantum dots for tumor cells.

The work of Coll et al. on the regioselectively addressable functionalized template RGD peptide (RAFT RGD) showed the specific labeling of tumor cells over-expressing integrin $\alpha \mathrm{V} \beta 3$ receptor. This molecule is a deca-peptide accepting 4 cyclo-RGD peptides and one fluorochrome of the cyanine 5 type. They showed that it was necessary to have at least 4 RGD peptides per platform to specifically detect tumor cells in vivo. ${ }^{4}$

Dendrimers are now experiencing their first major applications as diagnostic agents when grafted with contrast agents ${ }^{47,48}$ or fluorochromes $23,20,49$ and targeting agents. PAMAM dendrimers are used in imaging because they are water-soluble, biocompatible and biodegradable. ${ }^{50,51}$ They allow an increase in the sensitivity of detection because several imaging agents are bound per dendrimer. Furthermore, by increasing the number of biological probes by complex, it is possible in some cases to increase the specificity of the detection signal. The work of Hill and that of Thomas show the detection efficiency in fluorescence imaging of tumor cells in vivo by a complex composed of a PAMAM dendrimer with multiple RGD peptides ${ }^{52,53}$ and several fluorochromes. ${ }^{52,49}$ This approach can increase both the fluorescence signal of tumor probes and their specificity for tumor cells. Several studies 
using dendrimers as imaging agents are reported in Table 1.

Dendrimers are real molecular platforms that may also be grafted to drugs. These systems allow us to specifically target cells and provide local delivery of drugs in patients. ${ }^{54}$

\section{Conclusion}

In small animals, optical imaging is a low-cost technology by which tumor cells are detected over several weeks depending on the mouse strain. Wholebody imaging gives access to relative quantitative detection with a "crude" topological definition over a long period. The technology is rather simple and is now available on the market (Berthold, www.bertholdtech.com; Hamamatsu, www.hama-comp.com; Caliper Xenogen, www.caliperls. com; Fuji, www.fuji-sciences.com; Carestream, www.carestreamhealth.com; Cambridge Research Instrumentation, www.cri-inc.com; Biospace, www.biospacelab.com). This was recently reviewed as a technological feature in "Nature". Detection is associated with a light signal. The major limit is sensitivity and topological definition which remains associated with the turbidity of tissues. It could be improved by selecting the probes, light source and detector suitable for red fluorescence detection to avoid tissue absorption. More accurate data is obtained by other methods (intravital microscopy) but over a more limited period of time due to the associated surgery (Cellvizio, www. visualsonics.com; macrofluo, www.leica-microsystems.com; macroscope, www.nikoninstruments. eu). Real-time imaging of tumors by an IV injected probe sensitive to angiogenesis (AngioStamp ${ }^{\circledR}$, Angiosense), can be obtained by a user-friendly intra-operative imager $\left(\right.$ Fluobeam ${ }^{\circledR}$ ) that will drastically improve cancer surgery. Preclinical devices are available. The new ("smart") fluorescent probes associated with fluorescence endoscopy should help surgeons with tumor resection in the near future (Fluoptics, www.fluoptics.com; Visen, www.visenmedical.com). A preclinical study just showed a better survival over a 6-month period when tumors in the animal were resected by using a Cy5-labeled cell-penetrating peptide conjugated to a dendrimer to guide surgery. ${ }^{56}$

Therefore, following and quantifying tumor progression in vivo by optical imaging is a fantastic tool to monitor the expression of therapeutic genes in target tissues, in disease models and/or to assess the effectiveness of cancer therapies (surgery, ra- diotherapy, gene therapy). Added to the routinely used imaging techniques ${ }^{57,58}$, it can be used for diagnostic evaluation and surgical management.

\section{Acknowledgments}

Support from the Slovenian French Proteus program, from the ITAV program, from the Region Midi Pyrénées, from the ARC (Grand Sud) and from Biodendridots ANR project should be acknowledged.

\section{References}

1. Sodee DB, Conant R, Chalfant M, Miron S, Klein E, Bahnson R, et al. Preliminary imaging results using In-111 labeled CYT-356 (Prostascint) in the detection of recurrent prostate cancer. Clin Nucl Med 1996; 21: 759-67.

2. Nanus DM, Milowsky MI, Kostakoglu L, Smith-Jones PM, Vallabahajosula S, Goldsmith SJ, et al. Clinical use of monoclonal antibody HuJ591 therapy: targeting prostate specific membrane antigen. J Urol 2003; 170(6 Pt 2): S84-8; discussion S88-9.

3. Abdel-Nabi H, Doerr RJ, Chan HW, Balu D, Schmelter RF, Maguire RT. In-111labeled monoclonal antibody immunoscintigraphy in colorectal carcinoma: safety, sensitivity, and preliminary clinical results. Radiology 1990; 175: 163-71.

4. Moffat FL, Jr., Pinsky CM, Hammershaimb L, Petrelli NJ, Patt YZ, Whaley FS, et al. Clinical utility of external immunoscintigraphy with the IMMU-4 technetium-99m Fab' antibody fragment in patients undergoing surgery for carcinoma of the colon and rectum: results of a pivotal, phase III trial. The Immunomedics Study Group. J Clin Oncol 1996; 14: 2295-305.

5. Breitz HB, Tyler A, Bjorn MJ, Lesley T, Weiden PL. Clinical experience with Tc-99m nofetumomab merpentan (Verluma) radioimmunoscintigraphy. Clin Nucl Med 1997; 22: 615-20.

6. Weissleder R. A clearer vision for in vivo imaging. Nat Biotechnol 2001; 19: 316-7.

7. Wagnieres GA, Star WM, Wilson BC. In vivo fluorescence spectroscopy and imaging for oncological applications. Photochem Photobiol 1998; 68: 60332.

8. Rajwa B, Bernas T, Acker H, Dobrucki J, Robinson JP. Single- and two-photon spectral imaging of intrinsic fluorescence of transformed human hepatocytes. Microsc Res Tech 2007; 70: 869-79.

9. Troy T, Jekic-McMullen D, Sambucetti L, Rice B Quantitative comparison of the sensitivity of detection of fluorescent and bioluminescent reporters in animal models. Mol Imaging 2004; 3: 9-23.

10. Inoue $\mathrm{Y}$, Izawa K, Kiryu S, Tojo A, Ohtomo K. Diet and abdominal autofluorescence detected by in vivo fluorescence imaging of living mice. $\mathrm{Mol}$ Imaging 2008; 7: 21-7.

11. Weissleder $\mathrm{R}$, Ntziachristos $\mathrm{V}$. Shedding light onto live molecular targets. Nat Med 2003; 9: 123-8.

12. Chang K, Jaffer F. Advances in fluorescence imaging of the cardiovascular system. J Nucl Cardiol 2008; 15: 417-28.

13. Ballou B. Quantum dot surfaces for use in vivo and in vitro. Curr Top Dev Biol 2005; 70: 103-20.

14. Rao J, Dragulescu-Andrasi $\mathrm{A}$, Yao $\mathrm{H}$. Fluorescence imaging in vivo: recent advances. Curr Opin Biotechnol 2007; 18: 17-25.

15. Jin ZH, Josserand V, Razkin J, Garanger E, Boturyn D, Favrot MC, et al. Noninvasive optical imaging of ovarian metastases using Cy5-labeled RAFTc(-RGDfK-)4. Mol Imaging 2006; 5: 188-97.

16. Thomas TP, Patri AK, Myc A, Myaing MT, Ye JY, Norris TB, et al. In vitro targeting of synthesized antibody-conjugated dendrimer nanoparticles. Biomacromolecules 2004; 5: 2269-74. 
17. Zhang T, Stilwell JL, Gerion D, Ding L, Elboudwarej O, Cooke PA, et al Cellular effect of high doses of silica-coated quantum dot profiled with high throughput gene expression analysis and high content cellomics measurements. Nano Lett 2006; 6: 800-8.

18. Stroh M, Zimmer JP, Duda DG, Levchenko TS, Cohen KS, Brown EB, et al. Quantum dots spectrally distinguish multiple species within the tumor milieu in vivo. Nat Med 2005; 11: 678-82.

19. Lupold SE, Hicke BJ, Lin Y, Coffey DS. Identification and characterization of nuclease-stabilized RNA molecules that bind human prostate cancer cells via the prostate-specific membrane antigen. Cancer Res 2002; 62: 4029-33.

20. Patri AK, Myc A, Beals J, Thomas TP, Bander NH, Baker JR, Jr. Synthesis and in vitro testing of $J 591$ antibody-dendrimer conjugates for targeted prostate cancer therapy. Bioconjug Chem 2004; 15: 1174-81.

21. Lisy MR, Goermar A, Thomas C, Pauli J, Resch-Genger U, Kaiser WA, et al. In vivo near-infrared fluorescence imaging of carcinoembryonic antigenexpressing tumor cells in mice. Radiology 2008; 247: 779-87.

22. Chen $\mathrm{CH}$, Chernis GA, Hoang VQ, Landgraf R. Inhibition of heregulin signaling by an aptamer that preferentially binds to the oligomeric form of human epidermal growth factor receptor-3. Proc Natl Acad Sci USA 2003; 100: 9226-31.

23. Shukla R, Thomas TP, Peters IL, Desai AM, Kukowska-Latallo J, Patri AK, et al. HER2 specific tumor targeting with dendrimer conjugated anti-HER2 mAb. Bioconjug Chem 2006; 17: 1109-15.

24. Veiseh M, Gabikian P, Bahrami SB, Veiseh O, Zhang M, Hackman RC, et al. Tumor paint: a chlorotoxin:Cy5.5 bioconjugate for intraoperative visualization of cancer foci. Cancer Res 2007; 67: 6882-8.

25. Shukla R, Thomas TP, Peters J, Kotlyar A, Myc A, Baker Jr JR. Tumor ang iogenic vasculature targeting with PAMAM dendrimer-RGD conjugates. Chem Commun (Camb) 2005; 46: 5739-41.

26. Cai W, Chen X. Preparation of peptide-conjugated quantum dots for tumor vasculature-targeted imaging. Nat Protoc 2008; 3: 89-96.

27. Gunn AJ, Hama Y, Koyama Y, Kohn EC, Choyke PL, Kobayashi H. Targeted optical fluorescence imaging of human ovarian adenocarcinoma using galactosyl serum albumin-conjugated fluorophore. Cancer Sci 2007; 98: 1727-33.

28. Gao X, Cui Y, Levenson RM, Chung LW, Nie S. In vivo cancer targeting and imaging with semiconductor quantum dots. Nat Biotechnol 2004; 22: 96976.

29. Kaushal S, McElroy MK, Luiken GA, Talamini MA, Moossa AR, Hoffman RM et al. Fluorophore-conjugated anti-CEA antibody for the intraoperative imaging of pancreatic and colorectal cancer. J Gastrointest Surg 2008; 12: 1938-50.

30. Virostko J, Xie J, Hallahan DE, Arteaga CL, Gore JC, Manning HC. A molecular imaging paradigm to rapidly profile response to angiogenesis-directed therapy in small animals. Mol Imaging Biol 2009; 11: 204-12.

31. Takeda M, Tada H, Higuchi $H$, Kobayashi $Y$, Kobayashi $M$, Sakurai $Y$, et al. In vivo single molecular imaging and sentinel node navigation by nanotechnology for molecular targeting drug-delivery systems and tailor-made medicine. Breast Cancer 2008; 15: 145-52.

32. Kamaly N, Kalber T, Thanou M, Bell JD, Miller AD. Folate receptor targeted bimodal liposomes for tumor magnetic resonance imaging. Bioconjug Chem 2009; 20: 648-55.

33. Yang C, Ding N, Xu Y, Qu X, Zhang J, Zhao C, et al. Folate receptor-targeted quantum dot liposomes as fluorescence probes. J Drug Target 2009; 17: 502-11.

34. Ferreira CS, Matthews CS, Missailidis S. DNA aptamers that bind to MUC1 tumour marker: design and characterization of MUC1-binding singlestranded DNA aptamers. Tumour Biol 2006; 27: 289-301.

35. Perkins AC, Missailidis $S$. Radiolabelled aptamers for tumour imaging and therapy. Q J Nucl Med Mol Imaging 2007; 51: 292-6.

36. Charlton J, Sennello J, Smith D. In vivo imaging of inflammation using an aptamer inhibitor of human neutrophil elastase. Chemistry \& Biology 1997; 4: 809-16.

37. Hicke BJ, Stephens AW, Gould T, Chang YF, Lynott CK, Heil J, et al. Tumor targeting by an aptamer. J Nucl Med 2006; 47: 668-78.
38. Pieve CD, Perkins AC, Missailidis S. Anti-MUC1 aptamers: radiolabelling with $(99 \mathrm{~m}) \mathrm{Tc}$ and biodistribution in MCF-7 tumour-bearing mice. Nucl Med Biol 2009; 36: 703-10.

39. Bagalkot V, Zhang L, Levy-Nissenbaum E, Jon S, Kantoff PW, Langer R, et al. Quantum dot-aptamer conjugates for synchronous cancer imaging, therapy, and sensing of drug delivery based on bi-fluorescence resonance energy transfer. Nano Lett 2007; 7: 3065-70.

40. Razkin J, Josserand V, Boturyn D, Jin ZH, Dumy P, Favrot M, et al. Activatable fluorescent probes for tumour-targeting imaging in live mice. Chem Med Chem 2006; 1: 1069-72.

41. Bremer C, Bredow S, Mahmood U, Weissleder R, Tung CH. Optical imaging of matrix metalloproteinase-2 activity in tumors: feasibility study in a mouse model. Radiology 2001; 221: 523-9.

42. Reshetnyak YK, Andreev OA, Lehnert U, Engelman DM. Translocation of molecules into cells by $\mathrm{pH}$-dependent insertion of a transmembrane helix. Proc Natl Acad Sci USA 2006; 103: 6460-5.

43. Andreev OA, Dupuy AD, Segala M, Sandugu S, Serra DA, Chichester CO, et al. Mechanism and uses of a membrane peptide that targets tumors and other acidic tissues in vivo. Proc Natl Acad Sci USA 2007; 104: 7893-8.

44. Jin ZH, Razkin J, Josserand V, Boturyn D, Grichine A, Texier I, et al. In vivo noninvasive optical imaging of receptor-mediated RGD internalization using self-quenched Cy5-labeled RAFT-c(-RGDfK-)(4). Mol Imaging 2007; 6: 43-55.

45. Ballou B, Ernst LA, Waggoner AS. Fluorescence imaging of tumors in vivo. Curr Med Chem 2005; 12: 795-805.

46. Ntziachristos V, Bremer C, Weissleder R. Fluorescence imaging with nearinfrared light: new technological advances that enable in vivo molecular imaging. Eur Radiol 2003; 13: 195-208.

47. Swanson SD, Kukowska-Latallo JF, Patri AK, Chen C, Ge S, Cao Z, et al Targeted gadolinium-loaded dendrimer nanoparticles for tumor-specific magnetic resonance contrast enhancement. Int J Nanomedicine 2008; 3: 201-10.

48. Zhu W, Okollie B, Bhujwalla ZM, Artemov D. PAMAM dendrimer-based contrast agents for MR imaging of Her-2/neu receptors by a three-step pretargeting approach. Magn Reson Med 2008; 59: 679-85.

49. Thomas TP, Majoros IJ, Kotlyar A, Kukowska-Latallo JF, Bielinska A, Myc A et al. Targeting and inhibition of cell growth by an engineered dendritic nanodevice. J Med Chem 2005; 48: 3729-35.

50. Malik N, Wiwattanapatapee R, Klopsch R, Lorenz K, Frey H, Weener JW, et al. Dendrimers: relationship between structure and biocompatibility in vitro, and preliminary studies on the biodistribution of 1251-labelled polyamidoamine dendrimers in vivo. J Control Release 2000; 65: 133-48.

51. Xu R, Wang $Y$, Wang $X$, Jeong EK, Parker DL, Lu ZR. In vivo evaluation of a PAMAM-cystamine-(Gd-DO3A) conjugate as a biodegradable macromolecular MRI contrast agent. Exp Biol Med (Maywood) 2007; 232: 1081-9.

52. Hill E, Shukla R, Park SS, Baker JR, Jr. Synthetic PAMAM-RGD conjugates target and bind to odontoblast-like MDPC 23 cells and the predentin in tooth organ cultures. Bioconjug Chem 2007; 18: 1756-62.

53. Boswell CA, Eck PK, Regino CA, Bernardo M, Wong KJ, Milenic DE, et al. Synthesis, characterization, and biological evaluation of integrin alphavbeta3-targeted PAMAM dendrimers. Mol Pharm 2008; 5: 527-39.

54. Majoros IJ, Williams CR, Baker JR, Jr. Current dendrimer applications in cancer diagnosis and therapy. Curr Top Med Chem 2008; 8: 1165-79.

55. Baker M. Whole-animal imaging: The whole picture. Nature 2010; 463: $977-80$

56. Nguyen QT, Olson ES, Aguilera TA, Jiang T, Scadeng M, Ellies LG, et al. Surgery with molecular fluorescence imaging using activatable cell-penetrating peptides decreases residual cancer and improves survival. Proc Natl Acad Sci USA 2010; 107: 4317-22.

57. Yildirim M, Engin O, Oztekin O, Akdamar F, Adibelli ZH. Diagnostic evaluation and surgical management of recurrent hydatid cysts in an endemic region. Radiol Oncol 2009; 43:162-9.

58. Avazpour I, Roslan RE, Bayat P, Saripan MI, Nordin AJ, Azmir RS et al. Segmenting CT images of bronchogenic carcinoma with bone metastases using PET intensity markers approach. Radiol Oncol 2009; 43: 180-6. 